\title{
Contrução de cenários motivacionais sob a perspectiva de tecnologias sociais
}

Construction of motivational scenarios in the perspective of social technologies

\author{
> Adriane Borda Almeida da Silva \\ Universidade Federal de Pelotas, Brasil \\ adribord@hotmail.com
}

> Nirce Saffer Medvedovski

Universidade Federal de Pelotas, Brasil

nirce.sul@gmail.com]
> Sirlene de Mello Sopeña

Universidade Federal de Pelotas, Brasil

sirmellos@hotmail.com

> Gustavo Alcântara Brod

Universidade Federal de Pelotas, Brasil

gustavobrod@hotmail.com

\author{
> Theo Teodoro \\ Universidade Federal de \\ Pelotas, Brasil \\ Thalesteo.sn@gmail.com
}

\begin{abstract}
This paper describes the development of actions, denominated motivational scenarios, which sought to motivate behavior change in favor of the requalification of the urban space in a playful manner; the actions were directed to areas of social housing and the appreciation of architectural heritage. The concept of Social Technology and the recognition of advanced technologies of representation and visualization were characterized in this study as theoretical and technological framework respectively. The actions were structured from anamorphosis techniques, augmented reality and natural, tactile and motion-capture interfaces, building interactive virtual scenarios that are provocative in facing the architectural issues outlined.
\end{abstract}

Keywords: motivational scenarios; urban requalification, architectural heritage, natural interfaces and augmented realitys

\section{Introdução}

A caracterização de uma lata de lixo como um jogo, a qual a cada objeto depositado reage com som, em um espaço público, campanha publicitária realizada pela Volkswagen em 2009, exemplifica como uma ação de Design pode promover uma mudança de comportamento social através de estratégias divertidas. Sob outra perspectiva, na cidade do Rio de Janeiro, como exemplo, a lei 55/2013 dispóe sobre a aplicaçáo de multa ao cidadáo que for flagrado jogando lixo nos logradouros públicos. Ambas as açóes tem propósitos educativos, porém, utilizando-se de estratégias diferenciadas: diversão ou legislação e policiamento.

Neste trabalho relatam-se açóes que buscaram transpor a perspectiva lúdica de motivar mudanças de comportamento, sob dois propósitos advindos da área de arquitetura: requalificação do espaço urbano dirigido às áreas de Habitação de Interesse Social (HIS) e valorização de patrimônio arquitetônico.

O termo "cenários motivacionais" está sendo utilizado, no âmbito deste estudo, para caracterizar estas ações. A problemática foi incrementada a partir da associação do propósito de promover mudanças voluntárias de comportamento social ao conceito de Tecnologia Social (TS). Este conceito é abordado por Dagnino, 2001 e revisado por Kapp e Cardoso (2013), compreendendo-se que TS faz referência à tecnologia que não só objetiva promover a inclusão social e o estabelecimento de processos participativos de transformaçáo social. Mas, especialmente objetiva promover o empoderamento ou a aquisiçáo de critério individual e de consciência coletiva, necessários para uma transformação social. Especialmente,
Kapp e Cardoso (2013) consideram o poder de promover a "autonomia coletiva" o indicativo principal para que uma tecnologia seja caracterizada como Social.

Analisando-se a campanha da Volkswagen, citada anteriormente, sob o conceito em questão, passou-se a interpretá-la como um tipo de TS, por ter o potencial de provocar a formação de uma consciência coletiva. E, nesta direção, observa-se também a possibilidade de descrever os cenários motivacionais, referidos no âmbito deste trabalho, utilizando-se do conceito de Tecnologia Social. Parte-se do princípio que tais cenários buscam, igualmente, provocar mudanças de comportamento social, em prol das questóes abordadas, a partir de açôes voluntárias.

\section{Materiais e Métodos}

Além de considerar as especificidades dos temas tratados, o conceito de Tecnologia Social ficou entáo caracterizado como marco teórico do estudo, enquanto que o reconhecimento de tecnologias avançadas de representaçâo e visualização, atualmente disponíveis, ficou caracterizado como marco tecnológico. Estes referenciais determinaram os materiais e métodos empregados para o desenho dos "cenários motivacionais" para a requalificação do espaço urbano e a valorização de patrimônio arquitetônico, delimitando, para o desenvolvimento de cada cenário quatro etapas de estudo, descritas a seguir.

Etapa de revisão bibliográfica: $\mathrm{O}$ conceito de Tecnologia Social (TS) foi recentemente revisado e sistematizado por Kapp e Cardoso (2013), especificamente para a construção de um marco referencial 
para o desenvolvimento de projetos de produçáo e melhoria da moradia. Os referidos autores elaboraram diretrizes para o desenvolvimento de tecnologias sociais. Fundamentalmente, identificaram sete parâmetros, os quais, se presentes em conjunto, permitem caracterizar uma tecnologia como social. Em Medvedovski, Borda e Sopeña (2014), foi observada a pertinência de adotar estes sete parâmetros para analisar o potencial de TS das estratégias utilizadas para apoiar a execução de diagnóstico de contextos de habitação de interesse social, como açóes prévias ao projeto de requalificação do espaço urbano. Tais parâmetros são explicitados a seguir, destacando-se as adaptaçóes realizadas junto ao trabalho referido. $\mathrm{O}$ primeiro deles é a autonomia coletiva, indicada como diretriz que norteia todas as demais. O potencial de aumento ou de redução da autonomia é um critério de qualidade ou de desqualificação, respectivamente, de uma tecnologia social. Esta autonomia significa a possibilidade concreta, política, econômica, social e cultural, de "determinar" o tipo de processo. Nos termos originais destas diretrizes este processo está referido, especificamente, ao processo da habitação e de seus produtos. O segundo parâmetro é caracterizado pela capacidade da tecnologia de catalisação de processos coletivos. Observa a capacidade de promover a mobilização e organização populares, para transformar grupos em coletividades auto-organizadas. O terceiro parâmetro observa o potencial da tecnologia para a valorizaçáo do confronto. Esta característica é apontada como fundamental a ser atribuída à tecnologia, para promover o exercício do confronto e com isto afastar o mero participacionismo. Para Kapp e Cardoso (2013), o exercício do confronto possibilita uma compreensão das reais divergências de interesses, para que ocorram conquistas e não apenas concessóes. $\mathrm{O}$ quarto parâmetro se refere à capacidade de valorização dos pequenos ganhos de autonomia. Destaca para a importância de uma tecnologia responder às urgências, deixando o máximo de abertura para desenvolvimentos e transformaçóes ao longo do tempo. Não valoriza, desta maneira, a adoção de soluçôes pragmáticas conservadoras ou ainda de ideais emancipatórios inalcançáveis. O quinto indicativo de presença de tecnologia social refere-se à capacidade da tecnologia de fortalecimento de arranjos cooperativos. Nos termos originais, está dirigido especificamente para a construção civil. Visa favorecer relaçóes de produção em que também as pessoas (originalmente, os trabalhadores) adquiram maior autonomia para ampliar suas atuação política e suas qualificaçóes específicas. O sexto parâmetro se refere, nos termos de Kapp e Cardoso (2013), à necessidade de concepçáo da moradia como um processo. Destacam para a necessidade da moradia náo estar restrita à sequência convencional de um projeto, construçáo e uso, considerando o seu prolongamento no tempo. Referem-se à necessidade de soluçóes construtivas e organizacionais radicalmente flexíveis, adaptáveis e evolutivas. Este parâmetro foi interpretado no sentido de que as tecnologias analisadas, no caso, as estratégias de requalificação urbana, também devam ser concebidas como processos, flexíveis, adaptáveis e evolutivas. O sétimo e último parâmetro diz respeito à capacidade da tecnologia em promover a contextualizaçáo crítica. Este parâmetro decorre da consciência de que tecnologias náo seguem uma lógica apartada das sociedades e dos grupos em que se desenvolvem, contrapondo à crença de que tecnologias podem ser como que transplantadas de um contexto a outro. Esta etapa de revisão do conceito de TS foi oportunizada por um trabalho em rede de oito instituiçóes brasileiras, a rede MORAR.TS (http://www.mom.arq.ufmg.br/mom/27_finep/).

A revisão sobre as tecnologias avançadas de representação e visualização, para apoiar o processo de desenvolvimento dos cenários motivacionais foi também realizada no âmbito de um trabalho em rede, de oito instituiçóes latinoamericanas e quatro europeias, rede ALFA GAVIOTA (http://www.alfagaviota.eu/index.php/ el-proyecto). Apoiando-se na equipe interdisciplinar desta rede, de pesquisadores da área de informática gráfica e de arquitetura, foram reconhecidos conceitos e procedimentos relativos ao uso de tecnologias de edição de imagens, realidade virtual, aumentada, interfaces naturais, sejam táteis ou por captura de movimento, como recursos possíveis de serem utilizados para o desenvolvimento de tais cenários.

A etapa de projeto e desenvolvimento dos cenários foi realizada de acordo com a especificidade de cada propósito e de tecnologia adotada. Um trabalho prévio, relatado em Brod, Borda e Pires (2011), no qual foram utilizadas as técnicas de edição de imagens para a produção de anamorfose de um elemento do patrimônio arquitetônico da Cidade de Pelotas, RS, determinou o método de estudo para a estruturação de cenários tanto sob o tema de valorização do patrimônio arquitetônico quanto para a requalificação do espaço urbano.

A etapa de Experimentação está direcionada para as açóes que efetivamente envolvem a comunidade;

A etapa de Análise dos resultados frente ao conceito de tecnologia social e difusão.

\section{Resultados e Discussão}

Como resultados, até o momento, obtiveram-se o desenho de três tipos de "cenários motivacionais" e a experimentação e validação de dois deles.

O primeiro foi idealizado para ações de valorização de patrimônio arquitetônico, utilizando-se de técnicas de anamorfose. Collins (1992) relata que a anamorfose se refere à distorção da imagem de um objeto, de tal maneira que esta somente corresponde com a representação da forma deste objeto quando observada de um ponto de vista específico. Desta maneira, a partir da fotografia tirada de um determinado ponto de vista, uma imagem deformada de um elemento é percebida como se fosse um objeto tridimensional pertencente ao ambiente fotografado. Sob esta ilusão, a partir de instalaçóes em espaços públicos, foram representados diferentes elementos de interesse patrimonial da cidade de Pelotas. A figura 1 exemplifica duas destas instalaçóes, realizadas junto às comemoraçóes da Semana do Turismo de 2013 da cidade de Pelotas. As pessoas foram questionadas sobre a localização de tais elementos na cidade, estabelecendo um jogo de descobertas e motivando a curiosidade sobre o significado histórico de cada um para a cidade. A imagem da esquerda da figura 1, por exemplo, exemplifica a anamorfose da Torre do Mercado Central a qual foi representada em seu interior para destacar a riqueza do conjunto dos elementos em ferro deste edifício. A imagem ao centro desta mesma figura traz para o plano 


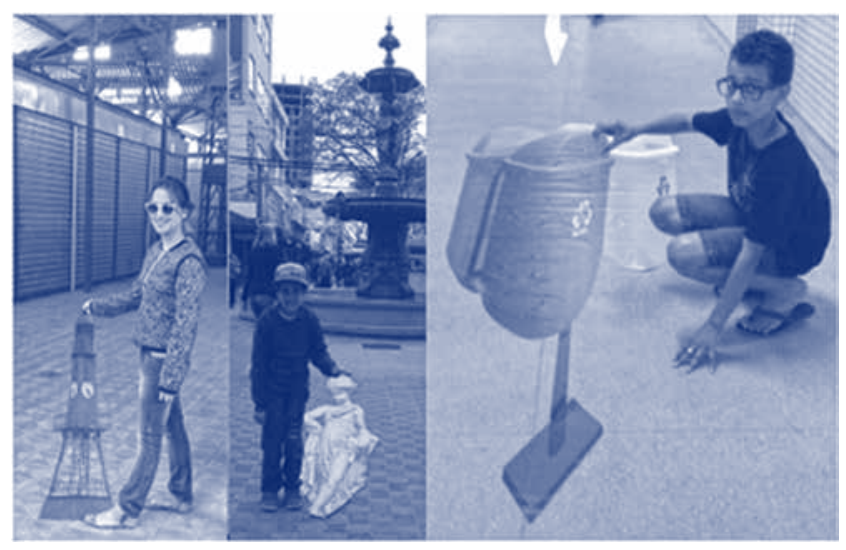

Figura I: Á esquerda, anamorfose da Torre do Mercado Central, ao centro, anamorfose de uma figura do Chafariz das três meninas, ambos elementos do Patrimônio da Cidade de Pelotas, à direita, anamorfose de uma lixeira. Fonte: dos autores, 2013.

do pedestre uma das esculturas do chafariz que está ao fundo, para muitos um elemento que foi descoberto a partir desta experiência, mesmo fazendo parte de seu cotidiano tal paisagem.

Depoimentos registrados sobre estas açóes demonstraram a eficácia para a educação patrimonial. Esta repercussão motivou o uso desta técnica também para o tema de requalificação do espaço urbano. Foram produzidas imagens anamórficas de elementos urbanos, como bancos e uma lixeira de coleta seletiva. Realizou-se uma instalação envolvendo a comunidade de um contexto de HIS. O caso da lixeira, por exemplo, promoveu um momento educativo: os sujeitos buscavam ser fotografados com um tipo de lixo na mão pertinente ao local destinado para o seu depósito, como ilustrado também junto à figura 1 .

O segundo cenário foi desenhado para apoiar a etapa de execução de um diagnóstico sobre um local a ser requalificado. A técnica até então utilizada no contexto trabalhado refere-se ao DRUP, Diagnóstico Rápido Urbano Participativo. Esta técnica se utiliza da coleta de dados a partir de um questionário e estabelece uma dinâmica de grupo para validar as respostas dadas pelos moradores de um determinado contexto urbano, de maneira participativa. Para apoiar este processo utiliza-se da fotografia como recurso para registrar o ponto de vista dos moradores sob os aspectos negativos do bairro. Buscando-se entáo outra estratégia para coletar dados

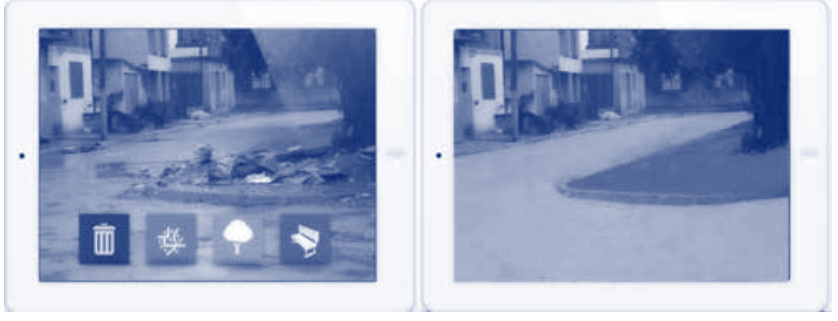

Figura 2: À esquerda, interface do jogo; à direita, transformação do cenário a partir do tratamento da imagem através da remoção do lixo. Fonte: dos autores, 2013. sobre o imaginário dos moradores, estruturou-se um jogo desenhado para computadores, tablets e para captura de movimento (kinect). O jogador pode remover elementos da cena fotografada. Para isto, tal fotografia é editada previamente. Os elementos apontados como indesejáveis pelos moradores são subtraídos, porém seguem sobrepostos à fotografia mantendo a aparência original. A interface disponibiliza um catálogo de elementos urbanos para serem selecionados e sobrepostos à imagem, compondo um cenário desejado pelo jogador. Este aplicativo, ilustrado pela figura 2, tem também a pretensão de "motivar a ação" para a requalificação efetiva do local representado, algumas vezes possível através da mudança de comportamento do próprio morador, como é o caso do depósito indevido de lixo no cenário urbano.

O terceiro cenário foi desenhado para intensificar o diálogo em projetos participativos de requalificação urbana. Esteve centrado no propósito de apresentar, a um contexto de autoconstrução, as transformaçóes possíveis de um espaço urbano decorrentes de decisóes individuais de cada morador, especificamente quanto aos temas de arborizaçáo e adensamento. A partir da análise das tendências de transformação de tal espaço, foram estruturados cenários, utilizando-se da técnica de Realidade Aumentada (RA). Sobrepondo-se assim elementos virtuais à realidade concreta, os cenários permitem que os moradores visualizem tais consequências. Como resultado tem-se a estruturação do método de construção de tais cenários, os quais objetivam então promover a construção de critérios, pelos moradores, para decidir sobre suas açóes: arborizar ou adensar. A figura 3 ilustra o tipo de cenário gerado.

Estâo sendo estruturados os materiais e momentos didáticos dirigidos às escolas da regiáo, os quais complementam as açóes a partir de oficinas. Tais oficinas objetivam o desenvolvimento de competências da comunidade envolvida para a utilização de técnicas de RA e para a ediçấo de imagens digitais, incluindo os efeitos de anamorfose.

\section{Considerações Finais}

O uso do conceito de TS, como marco teórico para o desenvolvimento desta investigação, tem possibilitado delimitar parâmetros que auxiliam na avaliação da pertinência de cada uma das açóes

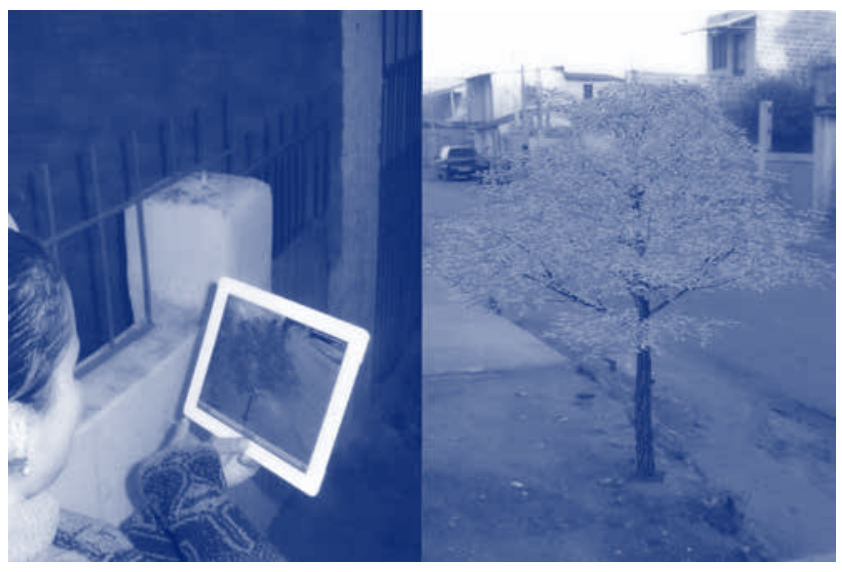

Figura 3: Requalificaçáo do espaço urbano através da inserçăo da vegetação em RA. Fonte: dos autores, 2013. 
propostas frente aos objetivos da investigação. O reconhecimento de tecnologias avançadas de visualizaçáo, adotado como marco tecnológico, tem permitido ampliar o repertório para a ação projetual.

Em relação ao cenário dirigido à valorização do patrimônio: considerou-se que a experiência de um sujeito ser provocado a identificar o local de um elemento representado em anamorfose e de ser questionado sobre o significado de tal elemento em termos patrimoniais motiva o desenvolvimento de um olhar mais atento, podendo configurar uma mudança de comportamento. Este cenário promove também a compreensão de técnicas de ilusão de ótica, atualmente veiculadas em situaçóes do cotidiano. Este conhecimento adquirido interpreta-se como uma açáo de empoderamento.

Em relação aos cenários dirigidos à requalificação do espaço urbano: considera-se a potencialidade de promoverem a construçáo de uma postura crítica, de tomada de consciência sobre as consequências das intervençôes decorrentes de decisôes individuais e coletivas sobre tal espaço. Esta construção de critérios interpreta-se também como empoderamento. Tais cenários fazem uso de tecnologias avançadas de visualização, contribuindo de alguma maneira para o reconhecimento e transferência de tecnologia.

As açôes formativas, as quais estão sendo estruturadas junto às escolas, buscam promover a autonomia da comunidade envolvida através da apropriação do conhecimento, postulados pelo conceito de TS.

Desta maneira, a investigação promoveu o desenho de três tipos de açôes, os quais permitiram exemplificar a possibilidade de uso de estratégias divertidas e/ou educativas para motivar a mudança de comportamento frente às questóes de interesse arquitetônico delimitadas no âmbito deste trabalho.

\section{Agradecimentos}

Aos órgãos financiadores CAPES, FINEP e Programa ALFA/CE..

\section{Referências}

Pires, J. F.; Nunes, C. S.; Vasconselos, T.; Silva, A. B. A. (2011). Trajetórias de Geometria na Arquitetura. In: XX GRAPHICA Simpósio Nacional de Geometria Descritiva e Desenho Técnico e International Conference on Graphics Engineering for Arts and Design, 2011, Rio de Janeiro. Anais...Rio de Janeiro: UFRJ, Escola de Belas Artes. 01-12.

Brod, G., Borda, A. e Pires, J. Anamorfose na praça: um encontro do real e do virtual In: XV SIGRADI - CONGRESSO DA
SOCIEDADE IBERO-AMERICANA DE GRÁFICA DIGITAL, Cultura Aumentada. Santa Fé - Argentina: FADU - UNL, 2011. v.1. p.130 - 133

Collins, D. (1992). Anamorphosis and the Eccentric Observer (part 1 and 2). Leonardo Journal, v. 25, n. 1 e 2, p. $73-82$, 179 - 187. São Francisco, EUA.

CUPERSCHMID, A.; RUSCHEL, R.; MONTEIRO, A.; Avaliação Do Reconhecimento De Modelos virtuais De Equipamentos Urbanos Para Áreas de Lazer em Realidade Aumentada, 11/2013, 6 Projetar - Ensino, Pesquisa e Prática 2013, Vol. 1, pp.1-21, Salvador, BA, Brasil, 2013.

DAGNINO, Renato. A Tecnologia Social e Seus Desafios. [s.l.]: [s.n.], 2001.

KAPP, Silke; CARDOSO, Adauto L. Moradia e tecnologias sociais: um extrato do marco teórico da rede Morar TS. In: Cardoso, Adauto L. Morar-TS Tecnologias Sociais aplicadas à Habitação de Interesse Social. Encontros nacionais da ANPUR: Desenvolvimento, planejamento e governança. Anais. Recife, 2013. 15v. Acesso em: 12/04/2013. Disponível em: http:// www.anpur.org.br/revista/rbeur/index.php/anais/ article / viewFile /4665/4533

MONTEIRO, E. "Verdes-dentro e Verdes-fora”: Visóes Prospectivas para Espaços Abertos Urbanos - Privados e Públicos - em Área Habitacional de Interesse Social. Tese (Doutorado), Campinas, SP: [s.n], 2007.

CARDOSO, Adauto. Tecnologias Sociais aplicadas à Habitação de Interesse Social. MORADIA E TECNOLOGIAS SOCIAIS: UM EXTRATO DO MARCO TEÓRICO DA REDE MORAR TS 2012. Disponível em: <http://www.anpur. org.br/ revista/rbeur/index.php/anais/article/viewFile/4665/4533>. Acesso em: 10/04/2013.

MEDVEDOVSKI, N, BORDA, A., SOPEÑA, S. ....ENTAC $2014 \ldots$

NAVARRO, Javier. Forma y Representación. Ediciones Akal. S. A., Madrid, 2008

TORI, R.; KIRNER, C.; SISCOUTTO, R. Fundamentos e Tecnologia de Realidade Virtual e Aumentada. Porto Alegre: SBC, 2006. 422p. Disponível em: <http://www.interlab.pcs. poli.usp.br. Acesso em 14/08/2011.

VOLKSWAGEN, 2009. Disponível em: <https://www.youtube. com/watch?v=1VosGS2-Hgg>. Acesso em: 05/09/2014. 